\title{
Exploration of Microbial Diversity and Community Structure of Lonar Lake: The Only Hypersaline Meteorite Crater Lake within Basalt Rock
}

\author{
Dhiraj Paul, Shreyas V. Kumbhare ${ }^{\dagger}$, Snehit S. Mhatre ${ }^{\dagger}$, Somak P. Chowdhury ${ }^{\dagger}$, \\ Sudarshan A. Shetty ${ }^{\dagger}$, Nachiket P. Marathe ${ }^{\dagger}$, Shrikant Bhute and Yogesh S. Shouche * \\ Microbial Culture Collection, National Centre for Cell Science, Savitribai Phule University of Pune Campus, Pune, India
}

\section{OPEN ACCESS}

Edited by:

Andreas Teske,

University of North Carolina at Chapel Hill, USA

Reviewed by:

Kasthuri Venkateswaran, NASA-Jet Propulsion Laboratory, USA

Maria Pachiadaki,

Woods Hole Oceanographic Institution, USA

*Correspondence:

Yogesh S. Shouche yogesh@nccs.res.in

${ }^{\dagger}$ These authors have contributed equally to this work

Specialty section

This article was submitted to

Extreme Microbiology,

a section of the journal

Frontiers in Microbiology

Received: 22 August 2015 Accepted: 21 December 2015 Published: 22 January 2016

Citation:

Paul D, Kumbhare SV, Mhatre SS,

Chowdhury SP, Shetty SA,

Marathe NP, Bhute $S$ and Shouche YS (2016) Exploration of Microbial Diversity and Community Structure of Lonar Lake: The Only Hypersaline

Meteorite Crater Lake within Basalt Rock. Front. Microbiol. 6:1553. doi: 10.3389/fmicb.2015.01553
Lonar Lake is a hypersaline and hyperalkaline soda lake and the only meteorite impact crater in the world situated in basalt rocks. Although culture-dependent studies have been reported, a comprehensive understanding of microbial community composition and structure in Lonar Lake remains elusive. In the present study, microbial community structure associated with Lonar Lake sediment and water samples was investigated using high-throughput sequencing. Microbial diversity analysis revealed the existence of diverse, yet largely consistent communities. Proteobacteria (30\%), Actinobacteria (24\%), Firmicutes (11\%), and Cyanobacteria (5\%) predominated in the sequencing survey, whereas Bacteroidetes (1.12\%), BD1-5 (0.5\%), Nitrospirae (0.41\%), and Verrucomicrobia $(0.28 \%)$ were detected in relatively minor abundances in the Lonar Lake ecosystem. Within the Proteobacteria phylum, the Gammaproteobacteria represented the most abundantly detected class (21-47\%) within sediment samples, but only a minor population in the water samples. Proteobacteria and Firmicutes were found at significantly higher abundance $(p \geq 0.05)$ in sediment samples, whereas members of Actinobacteria, Candidate division TM7 and Cyanobacteria $(p \geq 0.05)$ were significantly abundant in water samples. Compared to the microbial communities of other hypersaline soda lakes, those of Lonar Lake formed a distinct cluster, suggesting a different microbial community composition and structure. Here we report for the first time, the difference in composition of indigenous microbial communities between the sediment and water samples of Lonar Lake. An improved census of microbial community structure in this Lake ecosystem provides a foundation for exploring microbial biogeochemical cycling and microbial function in hypersaline lake environments.

Keywords: 16S rRNA gene, microbial diversity, soda lake, basalt rock, Lonar Lake, India

\section{INTRODUCTION}

Naturally occurring alkaline water bodies are unique and important ecosystems that offer valuable insights into how microbial communities cope with extreme growth conditions. High concentrations of carbonate and its complex salts, scarcity of $\mathrm{Mg}^{2+}$ and $\mathrm{Ca}^{2+}$, high salinity, especially due to $\mathrm{NaCl}$, and a high $\mathrm{pH}(9.0-12.0)$ are the hallmarks of these lakes (Wani et al., 2006; Antony et al., 2010; Sorokin et al., 2015). To date, a limited number of tropical lakes have 
been explored, especially those in the East African Rift Valley including Lake Nakuru and Lake Bogoria (Duckworth et al., 1996; Jones and Grant, 1999; Chandrasekhar et al., 2002; Vargas et al., 2004; Wani et al., 2006). Many of these alkaline lakes also have high productivity rates (Melack and Kilham, 1974; Grant, 2006) and contain microbial ecosystems that are active in nutrient and carbon cycling. However, a unified picture of microbial populations in these lakes has yet to emerge.

Lonar Lake is a tropical soda lake formed nearly 50,000 years ago due to a meteorite impact. It is the only example of an impact crater formed on volcanic flood basaltic rocks, making it geologically comparable to craters on the Martian surface (Fudali et al., 1980; Hagerty and Newsom, 2003). The lake is also a sink to a number of fresh water springs and streams with no discernible outlets (Joshi et al., 2008). Environmental constraints have selected for a distinctive microbial community; methylotrophs, purple- sulfur and non-sulfur photosynthetic bacteria, and other unusual bacteria such as Nitritalea halalkaliphila, Indibacter alkaliphilus, Cecembia lonarensis, and Georgenia satyanarayanai were isolated and reported from this lake (Jones et al., 1998; Zavarzin et al., 1999; Antony et al., 2010; Surakasi et al., 2010; Kumar et al., 2012; Srinivas et al., 2012; Sultanpuram et al., 2015). Microbial life in sediments of this lake was previously examined using clone libraries and Denaturant Gradient Gel Electrophoresis, revealing the presence of the bacterial phyla Firmicutes, Proteobacteria, and Actinobacteria (Wani et al., 2006; Surakasi et al., 2010). Since these technologies offer only limited resolution, the phylogenetic profile of this lake's microbial communities in water column and sediment remains rudimentary and only offers limited insights into associated microbial processes. The aim of this study is to obtain a detailed view of the bacterial diversity and community structure in Lonar Lake water and sediment using a high-throughput $16 \mathrm{~S}$ rRNA gene sequencing approach, to improve our understanding of autochthonous community composition within this complex and extreme lake ecosystem.

\section{MATERIALS AND METHODS}

\section{Site Description and Sampling}

Three sediment samples (S1, S2, and S3) from 40 to $50 \mathrm{~cm}$ depth and three corresponding water samples (W1, W2, and W3) from 10 to $20 \mathrm{~cm}$ depth used in this study were collected from three different locations $\left(19^{\circ} 98.222^{\prime} \mathrm{N}, 76^{\circ} 50.698^{\prime} \mathrm{E} ; 19^{\circ} 97.435^{\prime} \mathrm{N}\right.$, $76^{\circ} 50.342^{\prime} \mathrm{E} ; 19^{\circ} 97.532^{\prime} \mathrm{N}, 76^{\circ} 51.337^{\prime} \mathrm{E}$; respectively) of the Lonar Lake located in Buldhana district, Maharashtra, India during October 2013. The sediment samples from each site were collected using sterile scoopers in sterile polyethylene bags, while water samples were collected directly into sterile bottles. The surface temperature of the water was determined $\left(27^{\circ} \mathrm{C} \pm 0.5\right)$ on site. The $\mathrm{pH}$ values measured were within the range of 9.510.0. For the microbiological investigation, samples were stored immediately in ice and transported to the laboratory within $24 \mathrm{~h}$ and stored at $4^{\circ} \mathrm{C}$. Genomic DNA from the respective sediment and water samples was extracted within $72 \mathrm{~h}$ after sample collection and stored at $-20^{\circ} \mathrm{C}$. For chemical analysis, water samples were collected following the standard procedure that include filtering them through $0.45 \mu \mathrm{m}$ filter membrane for removing the debris particles and acidification with trace element grade $\mathrm{HNO}_{3}(\mathrm{pH} 2.0$ ), while the un-acidified filtered samples were collected for the analysis of major anions (Mukherjee et al., 2008).

\section{Analysis of Chemical Parameters}

Major anions $\left(\mathrm{SO}_{4}^{2-}, \mathrm{NO}_{3}^{-}, \mathrm{CO}_{3}^{-}\right.$, and $\left.\mathrm{Cl}^{-}\right)$of the samples were measured with an ion chromatograph (Dionex, USA). Total Fe, $\mathrm{Mg}, \mathrm{Co}, \mathrm{Ni}, \mathrm{B}$, and $\mathrm{Cu}$ were determined by atomic absorbance spectrometer (AAnalystTM 200, ParkinElmer, USA). Levels of $\mathrm{Na}, \mathrm{Ca}$, and $\mathrm{K}$ were quantified by using flame photometer (52A Flame Photometer Perkin-Elmer, USA). Total organic carbon (TOC), total nitrogen (TN), total dissolved solids (TDS), total phosphorus (TP), and $\mathrm{NH}_{3}$ were analyzed using standard methods (APHA, 1998).

\section{DNA Extraction from Samples}

Total DNA was extracted from all water and sediment samples using PowerWater DNA Extraction Kit (MoBio Laboratories, Inc., USA) and PowerSoil DNA Extraction Kit (MoBio Laboratories, Inc., USA), respectively. Briefly for water DNA extraction, $250 \mathrm{~mL}$ water was filtered through $0.22 \mu \mathrm{m}$ membrane filter and the filter paper was used for subsequent DNA extraction following manufacturer's instruction. Prior to sediment DNA extraction, all sediment samples were homogenized under aseptic conditions, and $250 \mathrm{mg}$ sediment was used for total DNA extraction using a PowerSoil DNA Kit (MoBio, Carlsbad, CA), following manufacturer's instructions. Yield and quality of the extracted DNA samples were checked on $0.8 \%$ agarose gel, and DNA concentration was measured using a NanoDrop ND-1000 spectrophotometer (Nano Drop technologies, Willingminton, USA). All the extracted DNA samples were stored at $-20^{\circ} \mathrm{C}$ until further processing.

\section{Preparation of 16S rRNA Gene Amplicon Libraries and Sequencing}

For amplicon library preparation, the universal primer set of 341F (5'-CCTACGGGAGGCAGCAG-3') and 518R (5'ATTACCGCGGCTGCTGG-3') specific for the V3 variable region of 16S rRNA gene were used (Bartram et al., 2011). The forward primer included Ion adaptor " $A$ " and barcode sequences and the reverse primer was attached to Ion adapter "p1" sequence. Details of the primers used are presented in Table S1. Each $50 \mu \mathrm{L}$ PCR reaction contained: $20 \mathrm{ng}$ of template DNA, $25 \mu \mathrm{L}$ AmpliTaq Gold 360 Master Mix (Life Technologies, Invitrogen division, Darmstadt, Germany) and $1.0 \mu \mathrm{L}$ of $10 \mathrm{mM}$ each primer. The PCR amplification was performed with an initial denaturation step at $94^{\circ} \mathrm{C}$ for $4 \mathrm{~min}$; followed by 35 cycles of denaturation at $94^{\circ} \mathrm{C}$ for $30 \mathrm{~s}$, annealing at $56^{\circ} \mathrm{C}$ for $30 \mathrm{~s}$, elongation at $72^{\circ} \mathrm{C}$ for $30 \mathrm{~s}$ and a final extension at $72^{\circ} \mathrm{C}$ for $10 \mathrm{~min}$. Post-amplification, amplicons were purified using 1.5X Agencourt AMPure XP Beads (Beckman Coulter, Inc., Brea, CA) following manufacturer's protocol. Prior to sequencing, all the amplicon products were assessed for fragment size distribution and DNA concentration using 
a Bioanalyzer 2100 (Agilent Technologies, USA). Further, 10 pM each amplified DNA fragments were attached to the surface of Ion Sphere Particles (ISPs) using an Ion Xpress Template $200 \mathrm{Kit}$ (Life Technologies, USA) and were clonally amplified through emulsion PCR, following the manufacturer's instructions. Sequencing of the amplicon libraries was carried out on an Ion Torrent PGM system (Life Technologies, USA) using 316 chip. After sequencing, all the individual sequence reads were filtered within the PGM software to remove low-quality reads, $3^{\prime}$ adaptor regions and polyclonal sequences.

\section{Ion Torrent Data Analysis}

After Ion Torrent PGM sequencing, the raw data was obtained in Fastq format. The pre-processing of the raw sequences, i.e., Fastq to Fasta file (sequence) conversion, qual (quality score), and data trimming were done by using MOTHUR version 1.34 .3 (http:// www.mothur.org/wiki) (Schloss et al., 2009) with the following conditions of minimum length: $130 \mathrm{bp}$, maximum length: $150 \mathrm{bp}$, maximum homopolymer: 5, maximum ambiguity: 0 and average quality score: 20 . The trimmed good quality sequences were merged into a single FASTA file for further analysis in QIIME v1.7 (Quantitative Insights Into Microbial Ecology) (http://qiime. org/) (Caporaso et al., 2010). The sequences were aligned to bacterial 16S rRNA gene sequence, and clustering or OTU picking was performed by using a reference-based OTU picking approach with Silva database (Silva_111_release, March 2015) (Pruesse et al., 2007). The OTU picking was carried out using UCLUST method with a similarity threshold of 97\% (Edgar, 2010). Taxonomic assignments were performed using RDP naïve Bayesian classifier (version rdp_classifier_2.10.1, released 29.10.2014) (Wang et al., 2007). Using QIIME, alpha diversity indices namely Chao1, ACE, Shannon, Simpsons' index, and Goods coverage were calculated. The sequences obtained from Ion Torrent sequencing are available at the NIH Sequence Read Archive (SRA) under the project accession number SRP059522.

\section{Statistical Analyses}

Experimental observations were recorded with three replications $(n=3)$ and data were expressed as mean \pm SD. Two-tailed paired $t$-tests were used for statistical analysis. Comparative analysis was performed to determine statistically significant structural differences within the sediment and water samples of Lonar Lake by two-sided Fisher exact tests using Statistical Analysis of Metagenomic Profiles (STAMP) program (Parks and Beiko, 2010). The co -occurrence and-exclusion of the bacterial groups in the sediment and water samples was performed using CoNet analysis (V.0.6) by Cytoscape (V-3.02) (Shannon et al., 2003). Five statistical measures were used for co-occurrence network analysis: Spearman and Pearson's measures of correlation and Hellinger distance, Kullback-Leibler dissimilarity, and Bray-Curtis dissimilarity measures. Statistical significance was assigned by measure specific and edge specific permutation and bootstrap scoring with 1000 iterations. The $p$ value was calculated by the $\mathrm{z}$-score distribution where high $p$ value signified co-exclusion and low $p$-value signified co-presence of the bacterial group in a particular habitat (Faust et al., 2012). The $p$-values retrieved from multiple statistical methods were merged by using Simes method. For multiple test correction, Benjamini-Hochberg correction was used $(p \geq 0.05)$. To obtain link among the connecting nodes, a minimum support of two statistical methods was used (Faust et al., 2012). The relationship among the samples with respect to family level distribution was ascertained using Unweighted Pair Group Method with Arithmetic Mean (UPGMA). In order to correlate bacterial community composition within the test samples and those previously reported from other soda lakes [(viz., Deep Lake (Colorado); Lake Chaka (China); Soap Lake (Washington); Organic Lake (Eastern Antarctica); Mono Lake (California); and Echo Lake (Colorado)], two UPGMA clustering was performed (details of all other samples used for this analysis is presented in Table S2). MVSP 3.1 software was used for UPGMA analysis (Paul et al., 2015).

\section{RESULTS}

\section{Geochemical Properties of Samples}

Geochemical properties of both water and sediment samples were analyzed to understand the physicochemical conditions in these microbial habitats. These samples differed markedly in terms of carbon-nitrogen stoichiometry, with water samples showing a lower C:N ratio compared to the sediments. All samples exhibited characteristic geochemical properties associated with a hypersaline soda lake, particularly with respect to $\mathrm{pH}$, salinity, TOC, total $\mathrm{N}$, total $\mathrm{P}, \mathrm{CO}_{3}^{2-}$, and $\mathrm{Cl}^{-}$content (Table $\mathbf{1}$ ). Additionally, geochemical analyses also revealed the presence of sulfates, ammonium and metals (such as $\mathrm{Ni}, \mathrm{Co}, \mathrm{Cu}$, and $\mathrm{Mg}$ ) in both sediment and water samples.

TABLE 1 | Physiochemical analysis of water and sediment samples.

\begin{tabular}{|c|c|c|}
\hline Chemical Parameters & Water & Sediment \\
\hline Total Dissolved Solids (TDS) (g/L) & $1.09 \pm 0.06$ & $1.04 \pm 0.02$ \\
\hline Total Organic Carbon (TOC) (g/L) & $0.002 \pm 0.0003$ & $0.25 \pm 0.05$ \\
\hline Total Nitrogen $(\mathrm{TN})(\mathrm{g} / \mathrm{L})$ & $0.004 \pm 0.0005$ & $0.19 \pm 0.03$ \\
\hline Total Phosphorus (P) as $\mathrm{PO}_{4}^{3-}(\mathrm{mg} / \mathrm{L})$ & $0.3 \pm 0.02$ & $3000.06 \pm 20.02$ \\
\hline Sodium as Sodium chloride ( $\mathrm{Na})(\mathrm{g} / \mathrm{L})$ & $3.8 \pm 0.09$ & $1.7 \pm 0.02$ \\
\hline Carbonates $\left(\mathrm{CO}_{3}^{-}\right)(\mathrm{g} / \mathrm{L})$ & $0.18 \pm 0.01$ & $0.23 \pm 0.03$ \\
\hline Chlorides $\left(\mathrm{Cl}^{-}\right)(\mathrm{g} / \mathrm{L})$ & $0.56 \pm 0.07$ & $0.21 \pm 0.06$ \\
\hline Ammonia $\left(\mathrm{NH}_{3}\right)(\mathrm{mg} / \mathrm{L})$ & $0.9 \pm 0.08$ & $3 \pm 0.02$ \\
\hline Sulfates $\left(\mathrm{SO}_{4}^{2-}\right)(\mathrm{mg} / \mathrm{L})$ & $0.004 \pm 0.0006$ & $50 \pm 3.84$ \\
\hline Calcium as (Ca) (mg/L) & $0.7 \pm 0.04$ & $520 \pm 3.02$ \\
\hline Cobalt as Co (mg/L) & $0.03 \pm 0.001$ & $2 \pm 0.31$ \\
\hline Nickel (Ni) (mg/L) & $0.01 \pm 0.002$ & $0.9 \pm 0.04$ \\
\hline Boron as B (mg/L) & $0.02 \pm 0.003$ & $1 \pm 0.2$ \\
\hline Magnesium as Mg (mg/L) & $1.7 \pm 0.5$ & $1100 \pm 8.94$ \\
\hline Potassium as K (mg/L) & $0.5 \pm 0.03$ & $50 \pm 1.83$ \\
\hline Iron as Fe (mg/L) & $0.09 \pm 0.001$ & $2000 \pm 10.93$ \\
\hline Copper as Cu (mg/L) & $0.002 \pm 0.0001$ & $5.3 \pm 0.512$ \\
\hline
\end{tabular}

All data represent mean of triplicate $( \pm) S D$. 


\section{Microbial Diversity Analysis}

Sequence datasets obtained after removal of low-quality sequences were trimmed, and only sequences of good quality were retained for subsequent analyses. A total of 11,90,896 high-quality sequences were obtained from all the samples. Taxonomic assignment of these sequences to define operational taxonomic units was based on a similarity threshold of $97 \%$. Good's coverage $(\geq 95 \%)$ indicated a high degree of sequence coverage (Table 2). Non-parametric indicators (ACE, Chao1, Simpson, and Shannon) were computed to evaluate community diversity characteristics of bacteria associated with hypersaline Lonar Lake sediments and the corresponding water samples. The assessment of diversity indices revealed differences in the complexity of bacterial communities in water and sediment samples from the lake, indicating the existence of a large bacterial community in Lonar Lake. Furthermore, when compared to sediment samples (S1, S2, S3), the corresponding water samples lacked both in diversity and complexity. Incidentally amongst sediment samples, S1 had the highest values of species richness indices of Chaol (73143.25), ACE (73189.04) and also a higher Shannon diversity index (10.93), followed by samples S2 and S3 (Table 2). Overall across all the samples Shannon indices exhibited the following trend: $\mathrm{W} 2<\mathrm{W} 3<\mathrm{W} 1<\mathrm{S} 3<\mathrm{S} 2<\mathrm{S} 1$, confirming a higher diversity of bacterial communities in the sediment samples as compared to the water samples (Table 2).

\section{Bacterial Community Composition and Structure}

A total of 28 bacterial phyla were detected in the Lonar Lake samples. The ten most abundant phyla contributed up to $88 \%$ of the total bacterial diversity (Figure 1). Taxonomic analysis based on relative abundance revealed Proteobacteria (30\%) to be the most predominant phyla followed by Actinobacteria (24\%), Firmicutes (11\%), Cyanobacteria (5\%), and Candidate division TM7. Bacteroidetes, BD1-5, Nitrospirae, Verrucomicrobia, and Spirochaetes represented a relatively minor portion of the total diversity (Figure 1).

Bacteria belonging to phylum Proteobacteria were ubiquitous and the most abundant bacterial phylum across all the samples. A relatively higher abundance of this phylum was observed across all sediment samples S3 (60.06\%), S1 (53.52\%), and S2 $(31.26 \%)$ as compared to the corresponding water samples, amongst which, the highest was W1 (34.72\%), followed by considerably lower abundances in samples W3 (15\%) and
W2 (9.1\%) (Figure 1A). Similarly, bacterial members of the phylum Firmicutes occurred at higher relative abundances in sediment samples (in S1 29.9\%; S2 18.79\%; and S3 16\%) than in the water sample W1 (13.6\%) (Figure 1A). In contrast, Actinobacteria, Candidate division TM7 and Cyanobacteria were more abundant in water samples, compared to the sediment samples (Figure 1A). Members of the Actinobacteria dominated the water samples (up to $80 \%$ in W3 sample) with a maximum of $4.5 \%$ detected in the sediment (sample S1). Likewise Cyanobacteria and Candidate division TM7 were more abundant in water samples at $30 \%$ (in sample W1) and $18 \%$ (in sample W3), in contrast, the sediment samples had $0.01 \%$ (S1 sample) and $0.01 \%$ (S2 sample), respectively. Certain bacterial groups including Chloroflexi, Acidobacteria, Deinococcus, Fibrobacteres, Gemmatimonadetes, Nitrospirae, and Spirochaetes were exclusive to sediment samples (Figure 1A). Within Proteobacteria, Alpha-, Beta-, Gamma-, and Epsilonproteobacteria were observed in all samples. Notably, members of Gammaproteobacteria were the most abundant (21-47\%) amongst the three sediment samples and water sample W1 and formed a minor (1.4-3.1\%) proportion of the remaining water samples (W2 and W3). Gammaproteobacteria were followed by Alphaproteobacteria in terms of relative abundance in sediment samples S1 (19.32\%), S3 (11.8\%), and water sample W1 (13.4\%) (Figure 1A). In contrast, Beta-, Delta-, and Epsilonproteobacteria were present across the samples in relatively lower abundance $(<1 \%)$. Amongst the uncultured Candidate divisions, members of Candidate division TM7 were the most abundant in the majority of the samples followed by members of Candidate divisions WS3, OP9, BRC1, and OD1 (Figure 1A). In summary, as compared to water samples, phyla Proteobacteria and Firmicutes were found to be significantly more abundant $(p=0.05)$ in sediment samples, whereas Actinobacteria followed by Candidate division TM7 and Cyanobacteria dominated the water samples of Lonar Lake (Figure 1B).

At the family level of taxonomic classification, a total of 216 common OTUs were observed in all the sediment samples with sample S1 containing the highest number of (44) unique OTUs (Figure 2A). Interestingly, water sample W1 (corresponding to sediment sample S1) also contained a higher number of unique OTUs (21) compared to the remaining water samples (Figure 2B). Only 159 OTUs could be assigned to the family level in our analysis. Among these, 21 OTUs were detected in all samples at $\geq 0.5 \%$ abundance and they were assigned

TABLE 2 | Sequence summary and calculation of alpha diversity indices of the sediment and water samples.

\begin{tabular}{|c|c|c|c|c|c|c|c|c|c|}
\hline \multirow[t]{2}{*}{ Sample ID } & \multirow[t]{2}{*}{ Sample nature } & \multirow[t]{2}{*}{ Raw reads } & \multirow[t]{2}{*}{ Assigned reads } & \multirow[t]{2}{*}{ OTUs } & \multirow[t]{2}{*}{ Coverage (\%) } & \multicolumn{4}{|c|}{ Richness and diversity indices } \\
\hline & & & & & & ACE & Chao1 & Shannon (H) & Simpsons (1/D) \\
\hline S1 & Sediment & 2000415 & 530536 & 515 & 0.98 & 73189.04 & 73143.25 & 10.93 & 0.994 \\
\hline S2 & Sediment & 996815 & 446224 & 396 & 0.96 & 53824.68 & 53563.58 & 10.23 & 0.989 \\
\hline S3 & Sediment & 209554 & 100577 & 383 & 0.95 & 36556.59 & 34211.12 & 10.01 & 0.977 \\
\hline W1 & Water & 245344 & 99230 & 119 & 0.97 & 10303.09 & 10349.17 & 8.09 & 0.975 \\
\hline W2 & Water & 20756 & 9142 & 62 & 0.95 & 1648.65 & 1654.78 & 6.82 & 0.967 \\
\hline W3 & Water & 11136 & 5187 & 93 & 0.95 & 2473.5 & 2247.17 & 7.77 & 0.984 \\
\hline
\end{tabular}


A

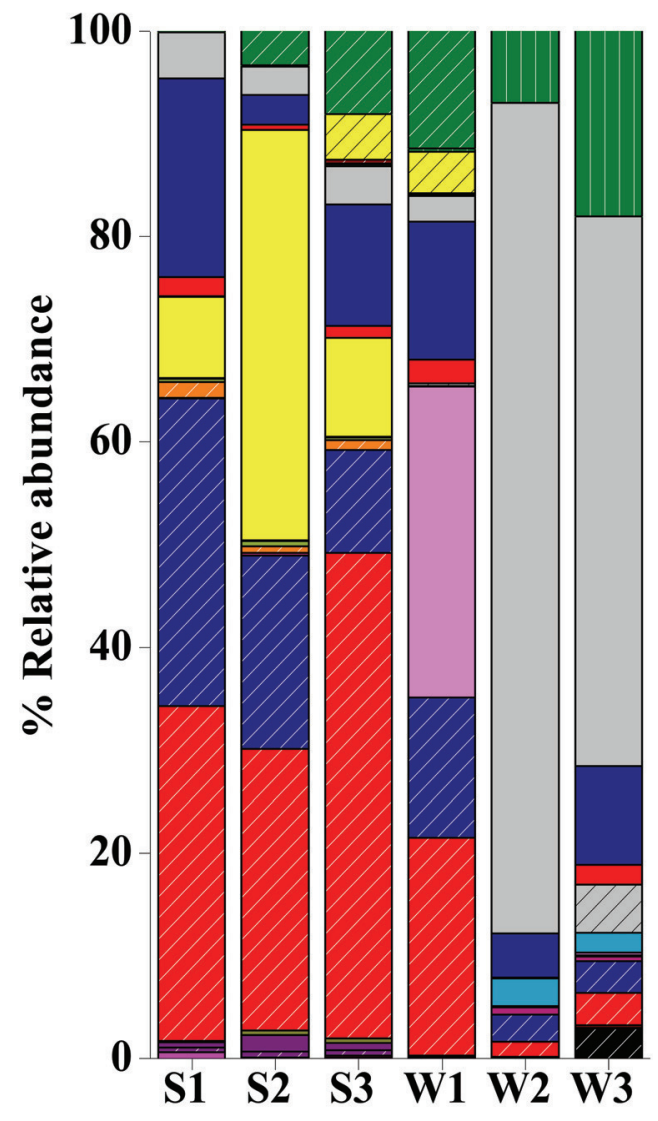

B

$95 \%$ confidence

Acidobacteria | Alphaproteobacteria Bacteroidetes BD1-5

Betaproteobacteria

Candidate division BRC1 |

Candidate division OD1

Candidate division OP9

Candidate division TM7

Candidate division WS3 Chloroflexi

Cyanobacteria

Deferribacteres

Deinococcus-Thermus

Deltaproteobacteria ?

Elusimicrobia |

Epsilonproteobacteria |

Fibrobacteres |

Firmicutes

Fusobacteria

Gammaproteobacteria

Gemmatimonadetes 1

Lentisphaerae |

Nitrospirae !

Planctomycetes

Spirochaetes 1

Synergistetes |

Tenericutes $\mid$

Thermotogae |

TM6 ।

Verrucomicrobia |

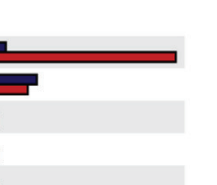

cor

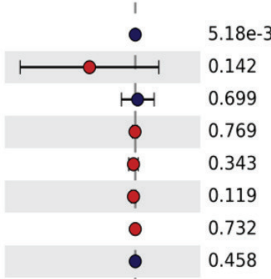

- 0.458

i) $\quad 0.943$

to- 0.177

1어 $\quad 0.997$

$\stackrel{\longrightarrow \longrightarrow}{\longrightarrow} 0.139$

$\mapsto \quad 0.365$

- 0.059 है

0.019

- $0.016 \stackrel{\varrho}{\Xi}$

0.121 零

- 0.254

- $6.92 \mathrm{e}-3$

Ho- 0.125

b $\quad 0.713$

$\longrightarrow 0.035$

0.025

0.317

- 0.045

- 0.049

- $4.98 \mathrm{e}-4$

0.256

0.282

0.195

P

\begin{tabular}{ll}
0 & 0.453 \\
\hline & 0.374
\end{tabular}
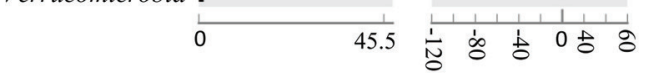

Mean proportion (\%) $\quad \begin{gathered}\text { Difference in } \\ \text { mean proportion (\%) }\end{gathered}$

\section{mean p}

\begin{tabular}{l}
\hline Gemmatimonadetes \\
\hline Lentisphaerae \\
Nitrospirae \\
Planctomycetes \\
\hline Spirochaetes \\
\hline Synergistetes \\
\hline Tenericutes \\
\hline Thermotogae \\
TM \\
TM \\
Verrucomicrobia
\end{tabular}



Actinobacteria

Alphaproteobacteria

Bacteroidetes

V7 BD1-5

Betaproteobacteria

Candidate division WS3

$\prod$ Candidate division TM7

VZ Candidate division OP9

Candidate division OD1

CZ Candidate division $\mathrm{BRC1}$

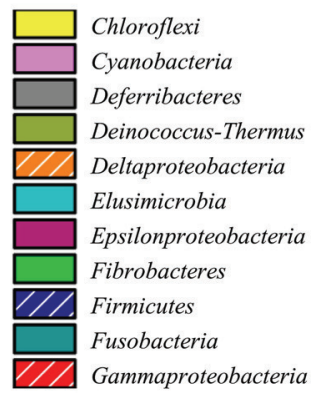

FIGURE 1 | Distribution of major phylogenetic groups of bacteria in (A) across the sediment and water samples, and (B) overall distribution between sediment and water samples of the Lonar Lake. Bacterial abundance in the sediment sample has a positive difference between proportions (blue circles), whereas bacterial abundance in the water sample has a negative difference between proportions (red circles). Bars on the left represent the proportion of each bacterial phyla abundance in the samples. Bacterial abundance difference with a $p$-value of $>0.05$ were considered to be significant.

to Acidimicrobiaceae, Microbacteriaceae, Nitriliruptoraceae (Actinobacteria), Bacillaceae, Staphylococcaceae, Clostridiaceae, Peptostreptococcaceae (Firmicutes), Hyphomonadaceae, Rhodobacteraceae (Alphaproteobacteria), Alcaligenaceae (Betaproteobacteria), Enterobacteriaceae, Pseudomonadaceae (Gammaproteobacteria) (Figure 3). Additionally, sediment samples had a higher relative abundance of Halomonadaceae, Oceanospirillaceae, Clostridiaceae, and Syntrophomonadaceae, whereas Streptococcaceae, Caulobacteraceae, and Planctomycetaceae predominated the water samples (Figure 3 and Figure S1). Members of the Verrucomicrobiaceae, Methylococcaceae, Piscirickettsiaceae, and Methylobacteriaceae were detected infrequently, occurring in four or fewer samples (Table S3). To understand the relatedness between samples analyzed, the Lonar Lake (sediment and water) samples were subjected to UPGMA at the family level of taxonomic 


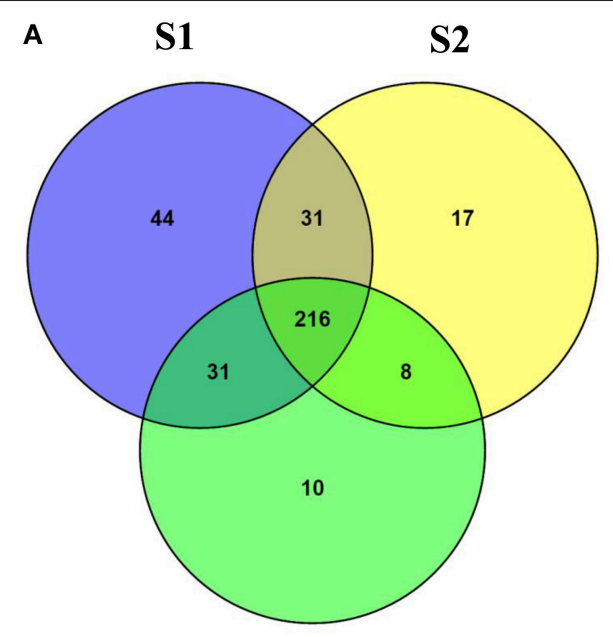

S3

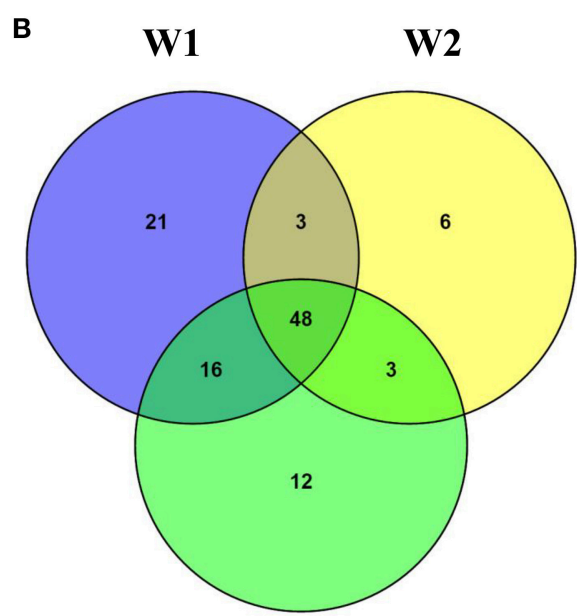

W3

FIGURE 2 | Venn diagram demonstrating unique and shared OTUs at family level (A) among the sediment samples and (B) among the water samples of the Lonar Lake.

distribution. Dendrogram analysis revealed that sediment samples shared high degree of relatedness as compared to their relatedness with the corresponding water samples (Figure 3).

\section{Statistical Analyses}

In order to discern interactions between different bacterial groups at the family level, we applied co-occurrence analysis to the sequence dataset. We were able to detect 1117 and 219 interactions in sediment and water samples, respectively. Over $99 \%$ of the bacteria in the sediment samples and $66 \%$ of the bacteria in the water samples correlated positively with each other (Figure 4), whereas $34 \%$ of the bacterial groups in the water samples correlated negatively. Co-occurrence analysis also indicated the co-presence of Phycosphaeraceae, Nocardioidaceae, Alteromonadaceae, Syntrophomonadaceae, and Peptostreptococcaceae in the lake sediment (Figure 4A). Furthermore, the bacterial families Desulfobacteraceae, Acidobacteraceae, and Alicyclobacillaceae were found to correlate positively with each other, suggesting a core anaerobic population involved in biogeochemical cycling of carbon and sulfur. In contrast, negative correlations were observed for the families Piscirickettsiaceae with Hyphomonadaceae, and Cryomorphaceae with Planococcaceae, in the sediment environment. In water samples, the families Pseudomonadaceae, Microbacteriaceae, and Clostridiaceae correlated positively with each other, while the Ruminococcaceae correlated negatively with Staphylococcaceae, Oceanospiraceae, and Lachnospiraceae (Figure 4B).

For identifying relationships among the samples analyzed here and among previously reported soda lake samples with respect to bacterial community composition, a UPGMA based statistical analysis was performed. The soda lakes considered for this analysis were: Mono Lake, California;
Chaka Lake, China; Ekho Lake, Colorado; Organic Lake, Eastern Antarctica; Deep Lake, Colorado; and Meromictic Soda Lake, Washington State. Previously published data combined with our data were used to compile a heat map based on relative abundance of individual phyla/class identified within the samples (Figure 5A). The comparison revealed that a number of taxonomic groups (Gammaproteobacteria, Bacteroidetes, Firmicutes, Alphaproteobacteria, and Betaproteobacteria) were observed consistently in geographically distinct hypersaline soda lakes. The analysis also demonstrated that other bacterial lineages (especially Actinobacteria, and Candidate divisions TM7) were conspicuous in Lonar Lake samples and Meromictic Soda Lake of Washington State samples, but not in other hypersaline soda lakes. The UPGMA based dendrogram indicated a strong relationship within Lonar Lake samples at or above a $50 \%$ similarity level (Figure 5B). Also, sample W1 (this study) was highly related to a sample from the Organic Lake (OL). Surprisingly, we observed a lack of relationship between results of our microbial census of Lonar Lake samples to a previously reported Lonar Lake sediment sample (LL). This unexpected finding could result from distinct time points of sample collection, seasonal variation, or differences in sample processing methodology. The Lonar Lake samples that were subjected to analysis in this study were dominated by Proteobacteria, Actinobacteria, Firmicutes, and Cyanobacteria whereas previous phylogenetic census revealed the dominance of Proteobacteria followed by Bacteroidetes, Planctomycetes, and Actinobacteria (Wani et al., 2006).

A second UPGMA was performed to analyze the relationship among the different bacterial groups present within the samples (Figure 5C). Evidently, Alpha-, Beta-, and Gammaproteobacteria, Acidobacteria, and Bacteroidetes were closely related across all the samples at $60 \%$ similarity level, suggesting their co-occurrence in a number of the hypersaline lake samples. Bacterial members 


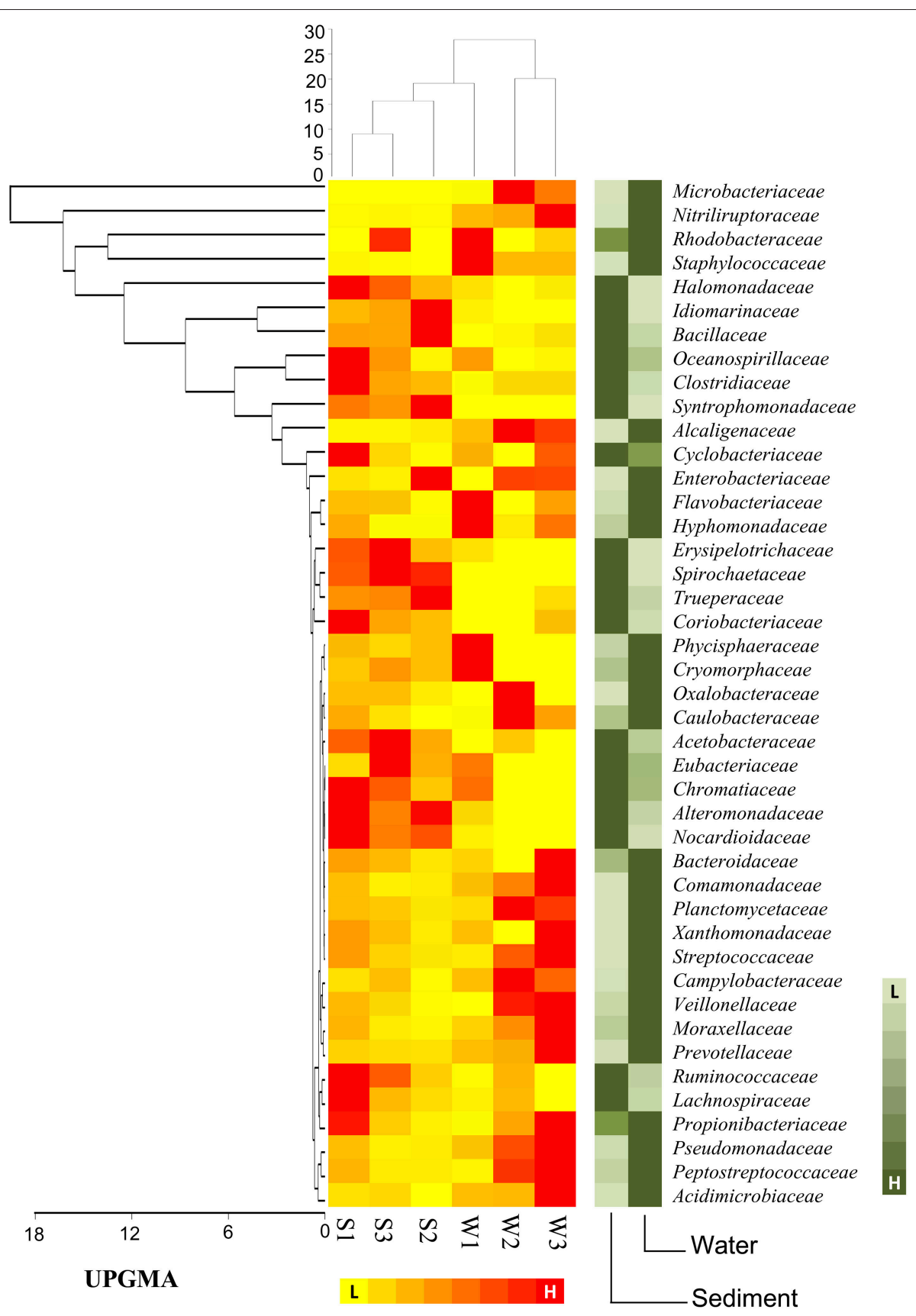

FIGURE 3 | Heat map shows distribution of major bacterial group (detected five or more than five samples) at family level.

of phyla Firmicutes, Bacteroidetes, and Gammaproteobacteria were abundant in a large proportion of studied soda lakes of the world including Lonar Lake (Figure 5D). Therefore, such analyses were not only able to estimate bacterial community composition among the diverse soda lake samples, but also identified bacterial phyla that might be favored in all hypersaline lakes. The abundance of these common bacterial groups in soda lakes clearly indicates their involvement in key aspects of a soda lake ecosystem.

\section{DISCUSSION}

This culture-independent molecular survey provides new insights into structure and composition of indigenous microbial communities within a meteorite impact hypersaline Lonar Lake ecosystem. The majority of bacterial members found in the samples belong to Proteobacteria, Actinobacteria, Firmicutes, and Candidate division TM7. Members of these groups were previously identified and reported in tropical soda lake 


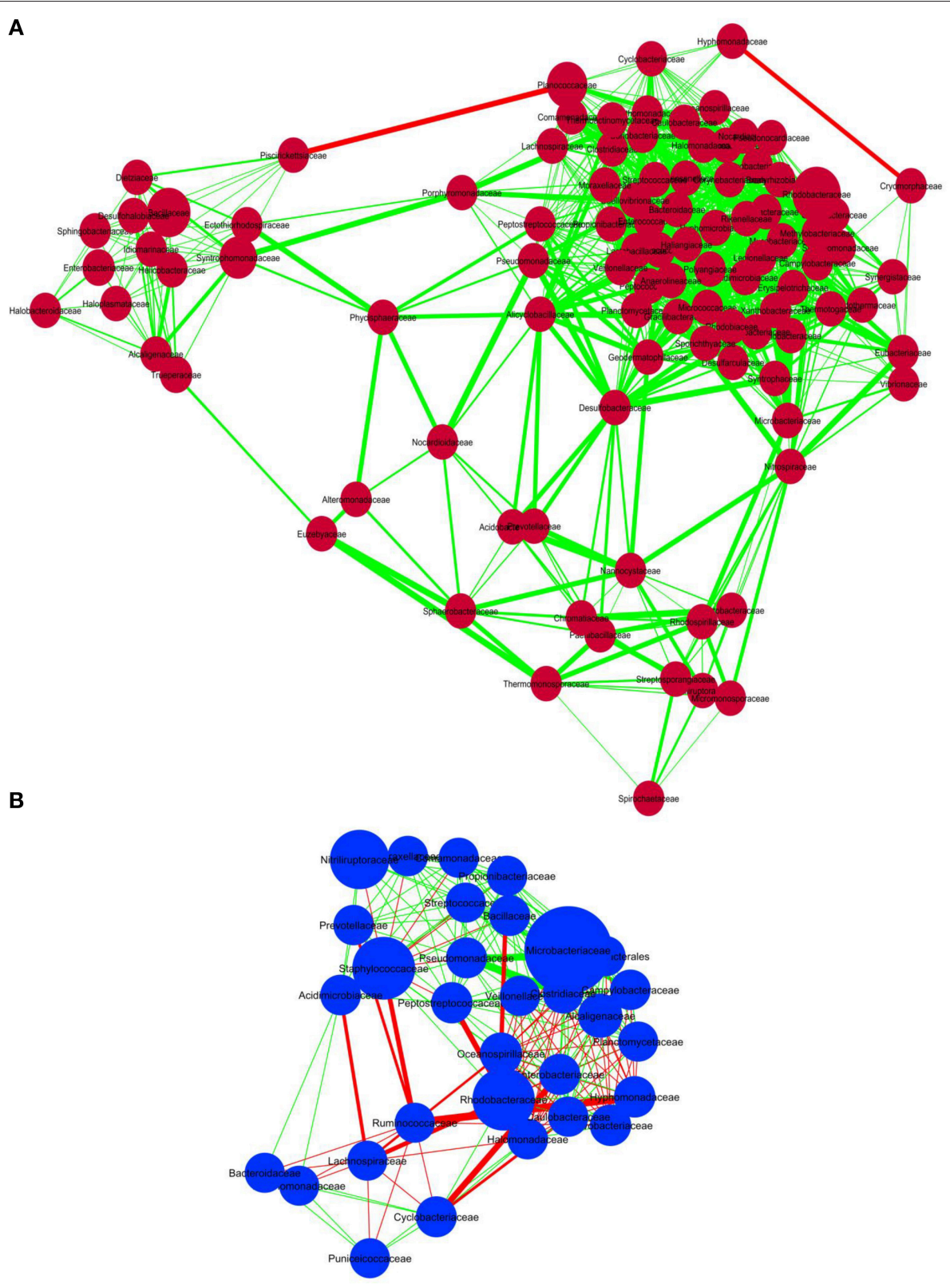

FIGURE 4 | Co-occurrence analysis of the bacteria members (A) sediment samples and (B) water samples of Lonar Lake at family level. Diagram shows the interactions among different bacteria. Red line indicates negative association and green line indicates positive association. The thickness of the line indicates strength of interaction and the size of the bubble indicates the relative abundance of bacterial members.

ecosystems such as Lake Nakuru and Lake Bogoria too in the African Rift Valley as well as from the Lonar Lake ecosystem, where they transform methane, sulfur, elemental nitrogen or nitrate in autotrophic and/or chemotrophic metabolism under aerobic as well as anaerobic conditions (Duckworth et al., 1996; Jones and Grant, 1999; Chandrasekhar et al., 2002; Vargas et al., 2004; Wani et al., 2006). Physicochemical analyses of sediment and water samples demonstrated that Lonar Lake has a comparable characteristic of hypersaline lake ecosystem, based primarily on $\mathrm{pH}$, salinity, TOC, and abundance of $\mathrm{CO}_{3}^{2-}$ (Chandrasekhar et al., 2002; Wani et al., 2006; Joshi et al., 2008;
Antony et al., 2010). Despite the existence of extreme alkaline and saline conditions in this lake, a diverse bacterial community was detected in the present study.

The sediment and water samples were distinct in terms of bacterial community composition. As indicated in previous studies, the bacterial community of the lake water in this study was also dominated by members of the Actinobacteria, Candidate division TM7 and WS3, and Cyanobacteria and sediment samples by Firmicutes and Proteobacteria (Chandrasekhar et al., 2002; Wani et al., 2006). Further, bacterial co-occurrence analysis showed a closer mutual association of bacterial 


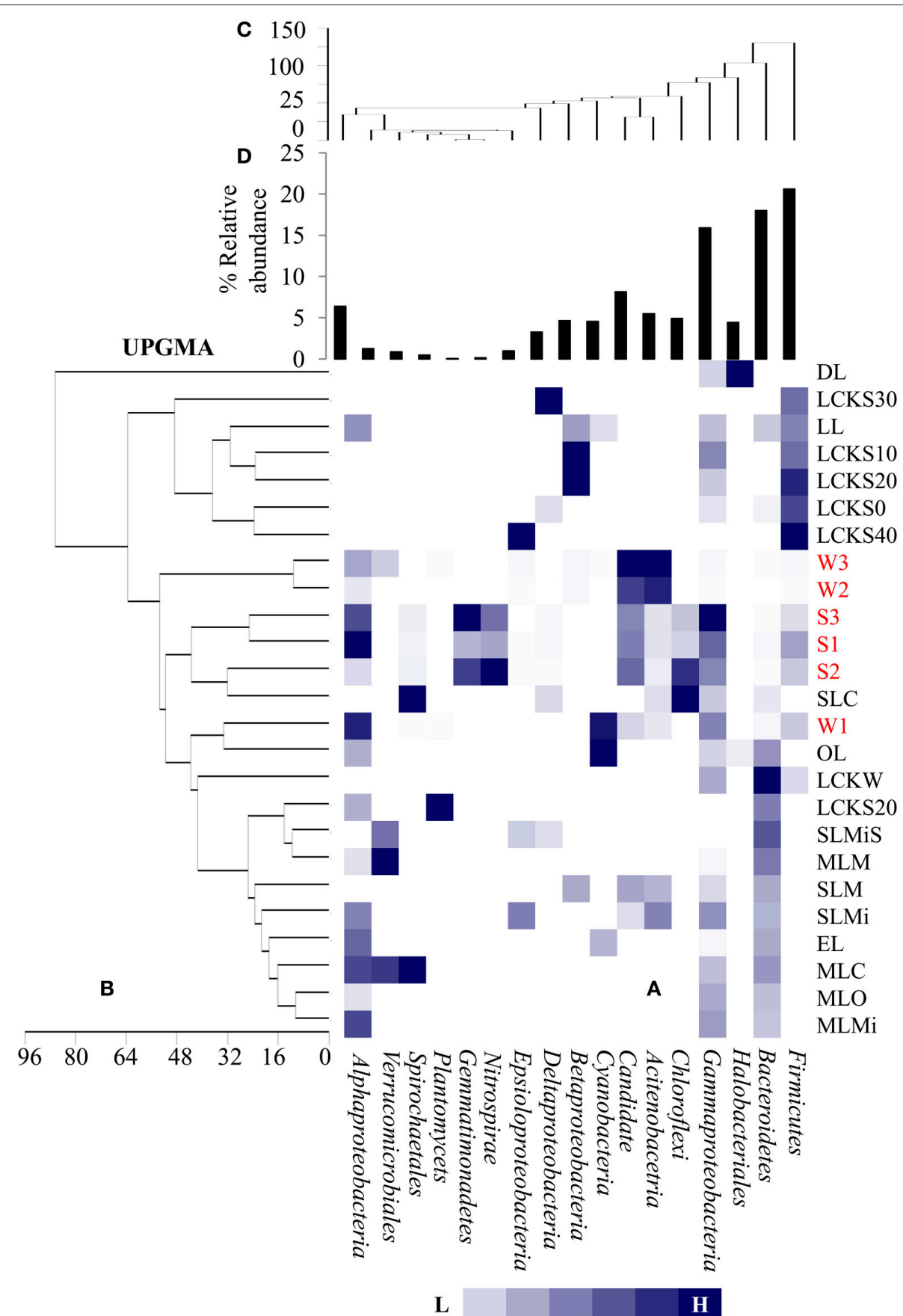

FIGURE 5 | Comparative analysis of bacterial community composition (A) among the present samples as well as those reported earlier from diverse hypersaline lake ecosystem, (B) UPGMA cluster analysis among the samples based on abundance of different bacterial groups as detected in different lake system, (C) UPGMA cluster analysis among the bacterial groups detected in diverse lake system and (D) relative abundance of the bacterial phylum. The samples are denoted as follows: DL, Deep Lake (Colorado); LCKS30, Lake Chaka (China); LL, Lonar Lake (India); LCKS10, Lake Chaka (China); LCKS20, Lake Chaka (China); LCKSO, Lake Chaka (China); LCKS40, Lake Chaka (China); W3, Lonar Lake water (present study); W2, Lonar Lake water (present study); S3, Lonar Lake sediment (present study); S1, Lonar Lake sediment (present study); S2, Lonar Lake sediment (present study); SLC, Soap Lake Chemocline (Washington); W1, Lonar Lake water (present study); OL, Organic Lake (Eastern Antarctica); LCKW, Lake Chaka (China); LCKS20, Lake Chaka (China); SLMiS, Soap Lake Mixolimnion sediment (Washington); MLM, Mono Lake Monimolimnion (California); SLM, Soap Lake Monimolimnion (Washington); SLMi, Soap Lake Mixolimnion (Washington); EL, Echo Lake (Colorado); MLC, Mono Lake Chemocline (California); MLO, Mono Lake Oxycline (California); MLMi, Mono Lake Mixolimnion (California). The details of these samples are provided as Supplementary Information (Table S2). 
community members in sediment samples, compared to water samples, suggesting competition for available resources being higher in the aquatic environment as compared to sediments (Faust et al., 2012). Syntrophic interactions between families like Synotrophomonadaceae in close associations with acetogenic families of Clostridiaceae were indicated by cooccurrence analysis, suggesting putative tightly controlled metabolite exchange in an extreme oligotrophic environment (Sieber et al., 2012). The chemical and physical limits of the habitat result in the development of co-existence or cooccurrence patterns within residing communities (Costello et al., 2009; Ofiteru et al., 2010; Langenheder and Székely, 2011). Possibly the higher abundance of different minerals (quartz, calcite, feldspars, etc.), halite salt, and reduced substances in sediments of Lonar Lake compared to water samples act as an abiotic control on microbial community composition (Wani et al., 2006; Antony et al., 2013). However, it could also be inferred that higher concentration of minerals and salts could also provide a suitable environment for the growth of many chemoheterotrophic bacteria. Therefore, the distinct patterns of bacterial community assembly across sediment and water are likely to be caused by differences in salinity, redox state and nutrient availability in this lake ecosystem.

Being a hypersaline environment, Lonar lake has a metabolically diverse halotolerant bacterial population. Within Proteobacteria, members of the Halomonadaceae, Oceanospirillaceae, and Pseudomonadaceae were prevalent in our taxonomic survey and have also been independently confirmed in such ecosystems using culture-based methods (Chandrasekhar et al., 2002; Wani et al., 2006; Joshi et al., 2008). These bacteria are known for their ubiquity and metabolic flexibility which includes their ability to tolerate extreme and/or oligotrophic environments, utilize diverse carbon compounds, and to maintain aerobic and anaerobic lifestyles (Brodie et al., 2006; Janssen, 2006; Wani et al., 2006). Additionally, Firmicutes were detected as a major group in Lonar Lake samples. Members of the Bacillaceae, Planococcaceae, and Staphylococcaceae were previously reported in various tropical alkaline lakes (Lake Nakuru, Lake Bogoria, and Lonar Lake) and were also observed in this study (Duckworth et al., 1996; Chandrasekhar et al., 2002; Vargas et al., 2004). They include members which are alkaliphiles, methylamine, methanol and dimethylsulfide utilizers, and have potential for metal resistance (Dijkhuizen et al., 1988; Anesti et al., 2005; Antony et al., 2010). Within Candidate divisions, members of Candidate division TM7 were found predominantly in water samples. Previously, the TM7 phylum was detected in a range of chemically and geographically diverse habitats, including groundwater, freshwater, seawater and deep-sea sediments (Hugenholtz et al., 2001; Di Rienzi et al., 2013; Basak et al., 2015; McLaughlin et al., 2015). Along with Candidate division TM7, the presence of other Candidate divisions namely WS3, OP9, and BRC1 in Lonar Lake may indicate a significant role for these groups in this lake ecosystem.

Lonar Lake sediment microbiota plays an important role in the utilization of $\mathrm{C} 1$ compounds. Previous investigations have suggested methanotrophy (Antony et al., 2010, 2013). A number of Proteobacterial families such as
Methylococcaceae, Piscirickettsiaceae (Gammaproteobacteria), and Methylobacteriaceae (Alphaproteobacteria) were detected during this investigation and have been biochemically implicated in cycling biogenic methane in sediments, which prevents its escape into the atmosphere, by oxidizing and assimilating methane-derived C1 compounds (Whalen et al., 1990; Hanson and Hanson, 1996; Antony et al., 2010). Sulfur-metabolizing bacteria, such as members of the Ectothiorhodospiraceae, Peptococcaceae, Desulfohalobiaceae, and Desulfonatronaceae, were also found in Lonar Lake as minor populations. These bacteria were previously identified as chemophototrophs (Ectothiorhospiraceae), or chemoheterotrophs (Peptococcaceae, Desulfohalobiaceae, and Desulfonatronaceae) which could utilize various inorganic sulfur compounds as electron donors or electron acceptors (Sorokin et al., 2006, 2011; Foti et al., 2007). Bacterial members of the family Ectothiorhodospiraceae are particularly remarkable in their ability to grow in saturated alkaline environments whereas Peptococcaceae, Desulfohalobiaceae, and Desulfonatronaceae are well known sulfate-reducing bacteria (Zhilina et al., 1997; Robertson et al., 2001; Pikuta et al., 2003). Hence, the co-occurrence of sulfuroxidizing and sulfate-reducing bacteria in soda lakes suggests the existence of a functionally linked intercycle coupling, i.e., redox junctions between $\mathrm{C}$ and $\mathrm{S}$ cycles. The sediments of hypersaline lakes contain a high level of a number of reduced substances, including inorganic compounds like sulfide or ammonia. Owing to the accumulation of such reduced substances at the bottom of the lake compared to water, the water column of hypersaline lakes may be deprived of essential nutrients (Jellison et al., 1996; Antony et al., 2010, 2013). In agreement with earlier studies, sediments showed a higher $\mathrm{C}: \mathrm{N}$ ratio along with increased ammonium, sulfate and phosphate concentrations compared to water samples; in turn, these results suggest increased nutrient turnover/mineralization and higher productivity in sediments of the lake. Hence, it is apparent that the geochemical gradients in Lonar Lake sediment and water samples contribute to the overall microbial structure in the lake, and also result in higher bacterial diversity/OTUs in Lonar Lake sediments, compared to the water column, thus bearing a clear influence on the activities of the indigenous microbial communities of the lake ecosystem.

\section{CONCLUSIONS}

We present here the first study to integrate a uniform framework of Lonar Lake sediment and water ecosystems from a microbiological aspect. Detailed 16S rRNA gene sequencing using high-throughput Ion torrent platform revealed a diverse and distinct landscape of bacterial fauna in both sediments and water samples with prevalence of the phyla Gammaproteobacteria, Alphaproteobacteria, Actinobacteria, Firmicutes, and Candidate divisions TM7 and WS3. Bacterial taxa of distinct phylogenetic clusters carry out central biogeochemical functions such as methylotrophy and sulfate reduction, and suggest complex biogeochemical interactions in this ecosystem that await specific functional characterization by targeted gene expression and geochemical studies. 


\section{AUTHOR CONTRIBUTIONS}

Conceived and designed the experiments: DP, SK, SM, SC, SS, NM, YS. Performed the experiments: SK, SM, SC, SS, NM, DP. Analyzed the data: DP, SB. Contributed reagents/materials/analysis tools: YS. Manuscript preparation: DP. Manuscript improvement: SC, DP, SK, SB, NM, SS.

\section{ACKNOWLEDGMENTS}

The authors acknowledge Department of Biotechnology (DBT), Government of India, (Grant number: BT/IN/FRG/09/YSS/2008) for financial support. Nachiket Marathe acknowledges Council of Scientific and Industrial research (CSIR), New Delhi, for fellowship. The authors are also grateful to Dr. Christopher J. Stewart (Baylor College of Medicine, Houston, Texas) for his help to improve the manuscript.

\section{REFERENCES}

Anesti, V., McDonald, I. R., Ramaswamy, M., Wade, W. G., Kelly, D. P., and Wood, A. P. (2005). Isolation and molecular detection of methylotrophic bacteria occurring in the human mouth. Environ. Microbiol. 7, 1227-1238. doi: 10.1111/j.1462-2920.2005.00805.x

Antony, C. P., Kumaresan, D., Ferrando, L., Boden, R., Moussard, H., Scavino, A. F., et al. (2010). Active methylotrophs in the sediments of Lonar Lake, a saline and alkaline ecosystem formed by meteor impact. ISME J. 4, 1470-1480. doi: 10.1038/ismej.2010.70

Antony, C. P., Kumaresan, D., Hunger, S., Drake, H. L., Murrell, J. C., and Shouche, Y. S. (2013). Microbiology of Lonar Lake and other soda lakes. ISME J. 7, 468-476. doi: 10.1038/ismej.2012.137

APHA (1998). Standard Methods for the Examination of Water and Waste Water, 20th Edn. Washington, DC: WEF.

Bartram, A. K., Lynch, M. D., Stearns, J. C., Moreno-Hagelsieb, G., and Neufeld, J. D. (2011). Generation of multimillion-sequence $16 \mathrm{~S}$ rRNA gene libraries from complex microbial communities by assembling paired-end Illumina reads. Appl. Environ. Microbiol. 77, 3846-3852. doi: 10.1128/AEM.02772-10

Basak, P., Majumder, N. S., Nag, S., Bhattacharyya, A., Roy, D., Chakraborty, A., et al. (2015). Spatiotemporal analysis of bacterial diversity in sediments of Sundarbans using parallel 16S rRNA gene tag sequencing. Microb. Ecol. 69, 500-511. doi: 10.1007/s00248-014-0498-y

Brodie, E. L., DeSantis, T. Z., Joyner, D. C., Baek, S. M., Larsen, J. T., Andersen, G. L., et al. (2006). Application of a high-density oligonucleotide microarray approach to study bacterial population dynamics during uranium reduction and reoxidation. Appl. Environ. Microbial. 72, 6288-6298. doi: 10.1128/AEM.00246-06

Caporaso, J. G., Kuczynski, J., Stombaugh, J., Bittinger, K., Bushman, F. D., Costello, E. K., et al. (2010). QIIME allows analysis of highthroughput community sequencing data. Nat. Methods 7, 335-336. doi: 10.1038/nmeth.f.303

Chandrasekhar, D. V., Mishra, D. C., Rao, G. P., and Rao, J. M. (2002). Gravity and magnetic signatures of volcanic plugs related to Deccan volcanism in Saurashtra, India and their physical and geochemical properties. EPSL 201, 277-292. doi: 10.1016/s0012-821x(02)00712-4

Costello, E. K., Lauber, C. L., Hamady, M., Fierer, N., Gordon, J. I., and Knight, R. (2009). Bacterial community variation in human body habitats across space and time. Science 326, 1694-1697. doi: 10.1126/science.1177486

Dijkhuizen, L., Arfman, N., Attwood, M. M., Brooke, A. G., Harder, W., and Watling, E. M. (1988). Isolation and initial characterization of thermotolerant methylotrophic Bacillus strains. FEMS Microbial. Lett. 52, 209-214. doi: 10.1111/j.1574-6968.1988.tb02597.x

\section{SUPPLEMENTARY MATERIAL}

The Supplementary Material for this article can be found online at: http://journal.frontiersin.org/article/10.3389/fmicb. 2015.01553

Supplementary Figure1 | Significant differences of bacterial abundance at family level as a result of a Fisher exact test between the sediment and water samples conducted with the STAMP program. Bacterial abundance in the sediment sample has a positive difference between proportions (blue circles), whereas bacterial abundance in the water sample has a negative difference between proportions (red circles). Bars on the left represent the proportion of each bacterial family abundance in the samples. Bacterial abundance difference with a $p$-value of $>0.05$ were considered to be significant.

Supplementary Table1 | Details of the primers use.

Supplementary Table2 | Details of the samples used for comparing microbial composition among other samples (Figure 5).

Supplementary Table3 | Bacterial family detect in less number of samples ( $\leq 4$ samples) of Lonar Lake.

Di Rienzi, S. C., Sharon, I., Wrighton, K. C., Koren, O., Hug, L. A., Thomas, B. C., et al. (2013). The human gut and groundwater harbor non-photosynthetic bacteria belonging to a new Candidate phylum sibling to Cyanobacteria. Elife 2:e01102. doi: 10.7554/elife.01102

Duckworth, A. W., Grant, W. D., Jones, B. E., and Van Steenbergen, R. (1996). Phylogenetic diversity of soda lake alkaliphiles. FEMS Microbiol. Ecol. 19, 181-191.

Edgar, R. C. (2010). Search and clustering orders of magnitude faster than BLAST Bioinformatics 19, 2460-2461. doi: 10.1093/bioinformatics/btq461

Faust, K., Sathirapongsasuti, J. F., Izard, J., Segata, N., Gevers, D., Raes, J., et al. (2012). Microbial co-occurrence relationships in the human microbiome. PLoS Comput Biol. 8:e1002606. doi: 10.1371/journal.pcbi.1002606

Foti, M., Sorokin, D. Y., Lomans, B., Mussman, M., Zacharova, E. E., Pimenov, N. V., et al. (2007). Diversity, activity, and abundance of sulfate-reducing bacteria in saline and hypersaline soda lakes. Appl. Environ. Microbiol. 73, 2093-2100. doi: 10.1128/AEM.02622-06

Fudali, R. F., Milton, D. J., Fredriksson, K., and Dube, A. (1980). Morphology of Lonar crater, India: comparisons and implications. Moon Planets 23, 493-515. doi: 10.1007/BF00897591

Grant, W. D. (2006). Alkaline Environments and Biodiversity. Oxford: UNESCO; Eolss Publishers; Extremophiles.

Hagerty, J. J., and Newsom, H. E. (2003). Hydrothermal alteration at the Lonar Lake impact structure, India: implications for impact cratering on Mars. Metorit. Planet Sci. 38, 365-381. doi: 10.1111/j.1945-5100.2003.tb 00272.x

Hanson, R. S., and Hanson, T. E. (1996). Methanotrophic bacteria. Microbiol. Rev. 60, 439-471.

Hugenholtz, P., Tyson, G. W., Webb, R. I., Wagner, A. M., and Blackall, L. L. (2001). Investigation of candidate division TM7, a recently recognized major lineage of the domain bacteria with no known pure-culture representatives. Appl. Environ. Microbiol. 67, 411-419. doi: 10.1128/AEM.67.1.411419.2001

Janssen, P. H. (2006). Identifying the dominant soil bacterial taxa in libraries of $16 \mathrm{~S}$ rRNA and 16S rRNA genes. Appl. Environ. Microbial. 72, 1719-1728. doi: 10.1128/AEM.72.3.1719-1728.2006

Jellison, R., Anderson, R. F., Melack, J. M., and Heil, D. (1996). Organic matter accumulation in sediments of hypersaline Mono Lake during a period of changing salinity. Limnol. Oceanogr. 41, 1539-1544. doi: 10.4319/lo.1996.41.7.1539

Jones, B. E., and Grant, W. D. (1999). "Microbial diversity and ecology of the Soda Lakes of East Africa," in Microbial Biosystems: New Frontiers: Proceedings of the 8th International Symposium for Microbial Ecology (2000) Atlantic Canada Society for Microbial Ecology (Halifax, NS), 681-687. 
Jones, B. E., Grant, W. D., Duckworth, A. W., and Owenson, G. G. (1998). Microbial diversity of soda lakes. Extremophiles 2, 191-200. doi: $10.1007 / \mathrm{s} 007920050060$

Joshi, A. A., Kanekar, P. P., Kelkar, A. S., Shouche, Y. S., Vani, A. A., Borgave, S. B., et al. (2008). Cultivable bacterial diversity of alkaline Lonar Lake, India. Microb. Ecol. 55, 163-172. doi: 10.1007/s00248-007-9264-8

Kumar, S., Karan, R., Kapoor, S., Singh, S. P., and Khare, S. K. (2012). Screening and isolation of halophilic bacteria producing industrially important enzymes. Braz. J. Microbiol. 43, 1595-1603. doi: 10.1590/S1517-83822012000400044

Langenheder, S., and Székely, A. J. (2011). Species sorting and neutral processes are both important during the initial assembly of bacterial communities. ISME J. 5, 1086-1094. doi: 10.1038/ismej.2010.207

McLaughlin, R. W., Wang, S., Zhou, W., Cheng, G., and Deng, K. (2015). A comparison of the bacterial diversity of two shallow freshwater lakes in China. Proc. Natl. Acad. Sci. India Sect. B 85, 137-146. doi: 10.1007/s40011-013-0250-2

Melack, J. M., and Kilham, P. (1974). Photosynthetic rates of phytoplankton in East African alkaline, saline lakes. Limnol. Oceanogr. 19, 743-755. doi: 10.4319/lo.1974.19.5.0743

Mukherjee, A., von Brömssen, M., Scanlon, B. R., Bhattacharya, P., Fryar, A. E., Hasan, M. A., et al. (2008). Hydrogeochemical comparison and effects of overlapping redox zones on groundwater arsenic near the Western (Bhagirathi sub-basin, India) and Eastern (Meghna sub-basin, Bangladesh) margins of the Bengal Basin. J. Contam. Hydrol. 99, 31-48. doi: 10.1016/j.jconhyd.2007.10.005

Ofiteru, I. D., Lunn, M., Curtis, T. P., Wells, G. F., Criddle, C. S., Francis, C. A., et al. (2010). Combined niche and neutral effects in a microbial wastewater treatment community. Proc. Natl. Acad. Sci. U.S.A. 107, 15345-15350. doi: 10.1073/pnas. 1000604107

Parks, D. H., and Beiko, R. G. (2010). Identifying biologically relevant differences between metagenomic communities. Bioinformatics 26, 715-721. doi: 10.1093/bioinformatics/btq041

Paul, D., Kazy, S. K., Gupta, A. K., Pal, T., and Sar, P. (2015). Diversity, metabolic properties and arsenic mobilization potential of indigenous bacteria in arsenic contaminated groundwater of West Bengal, India. PLoS ONE 10:e118735. doi: 10.1371/journal.pone.0118735

Pikuta, E. V., Hoover, R. B., Bej, A. K., Marsic, D., Whitman, W. B., Cleland, D., et al. (2003). Desulfonatronum thiodismutans sp. nov., a novel alkaliphilic, sulfate-reducing bacterium capable of lithoautotrophic growth. Int. J. Syst. Evol. Microbial. 53, 1327-1332. doi: 10.1099/ijs.0.02598-0

Pruesse, E., Quast, C., Knittel, K., Fuchs, B. M., Ludwig, W., Peplies, J., et al. (2007). SILVA: a comprehensive online resource for quality checked and aligned ribosomal RNA sequence data compatible with ARB. Nucleic Acids Res. 35, 7188-7196. doi: 10.1093/nar/gkm864

Robertson, W. J., Bowman, J. P., Franzmann, P. D., and Mee, B. J. (2001). Desulfosporosinus meridiei sp. nov., a spore-forming sulfate-reducing bacterium isolated from gasolene-contaminated groundwater. Int. J. Syst. Evol. Microbial. 51, 133-140. doi: 10.1099/00207713-51-1-133

Schloss, P. D., Westcott, S. L., Ryabin, T., Hall, J. R., Hartmann, M., Hollister, E. B., et al. (2009). Introducing mothur: open-source, platformindependent, community-supported software for describing and comparing microbial communities. Appl. Environ. Microbiol. 75, 7537-7541. doi: 10.1128/AEM.01541-09

Shannon, P., Markiel, A., Ozier, O., Baliga, N. S., Wang, J. T., Ramage, D., et al. (2003). Cytoscape: a software environment for integrated models of biomolecular interaction networks. Genome Res. 13, 2498-2504 doi: $10.1101 /$ gr.1239303

Sieber, J. R., McInerney, M. J., and Gunsalus, R. P. (2012). Genomic insights into syntrophy: the paradigm for anaerobic metabolic cooperation. Annu. Rev. Microbiol. 66, 429-452. doi: 10.1146/annurev-micro-090110-102844
Sorokin, D. Y., Banciu, H. L., and Muyzer, G. (2015). Functional microbiology of soda lakes. Curr. Opin. Microbiol. 25, 88-96. doi: 10.1016/j.mib.2015. 05.004

Sorokin, D. Y., Banciu, H., Robertson, L. A., and Kuenen, J. G. (2006). "Haloalkaliphilic sulfur-oxidizing bacteriam," in The Prokaryotes, eds M. Dworkin, S. Falkow, E. Rosenberg, K.-H. Schleifer, and E. Stackebrandt (New York, NY: Springer), 969-984.

Sorokin, D. Y., Kuenen, J. G., and Muyzer, G. (2011). The microbial sulphur cycle at extremely haloalkaline conditions of soda lakes. Front. Microbiol. 2:44. doi: 10.3389/fmicb.2011.00044

Srinivas, A., Rahul, K., Sasikala, C., Subhash, Y., Ramaprasad, E. V. V., and Ramana, C. V. (2012). Georgenia satyanarayanai sp. nov., an alkaliphilic and thermotolerant amylase-producing actinobacterium isolated from a soda lake. Int. J. Syst. Evol. Microbiol. 62, 2405-2409. doi: 10.1099/ijs.0. 036210-0

Sultanpuram, V. R., Mothe, T., and Mohammed, F. (2015). Salisediminibacterium haloalkalitolerans sp. nov., isolated from Lonar soda lake, India, and a proposal for reclassification of Bacillus locisalis as Salisediminibacterium locisalis comb. nov., and the emended description of the genus Salisedimini bacterium and of the species Salisediminibacterium halotolerans. Arch. Microbiol. 197, 533-560. doi: 10.1007/s00203-015-1081-8

Surakasi, V. P., Antony, C. P., Sharma, S., Patole, M. S., and Shouche, Y. S. (2010). Temporal bacterial diversity and detection of putative methanotrophs in surface mats of Lonar crater lake. J. Basic Microbiol. 50, 465-474. doi: 10.1002/jobm.201000001

Vargas, V. A., Delgado, O. D., Hatti-Kaul, R., and Mattiasson, B. (2004). Lipaseproducing microorganisms from a Kenyan alkaline soda lake. Biotechnol. Lett. 26, 81-86. doi: 10.1023/B:BILE.0000012898.50608.12

Wang, Q., Garrity, G. M., Tiedje, J. M., and Cole, J. R. (2007). Naive Bayesian classifier for rapid assignment of rRNA sequences into the new bacterial taxonomy. Appl. Environ. Microbiol. 73, 5261-5267. doi: 10.1128/AEM. 00062-07

Wani, A. A., Surakasi, V. P., Siddharth, J., Raghavan, R. G., Patole, M. S., Ranade, D., et al. (2006). Molecular analyses of microbial diversity associated with the Lonar soda lake in India: an impact crater in a basalt area. Res. Microbiol. 157, 928-937. doi: 10.1016/j.resmic.2006.08.005

Whalen, S. C., Reeburgh, W. S., and Sandbeck, K. A. (1990). Rapid methane oxidation in a landfill cover soil. Appl. Environ. Microbiol. 56, 3405-3411.

Zavarzin, G. A., Zhilina, T. N., and Kevbrin, V. V. (1999). The alkaliphilic microbial community and its functional diversity. Microbiology 68, 503-521.

Zhilina, T. N., Zavarzin, G. A., Rainey, F. A., Pikuta, E. N., Osipov, G. A., and Kostrikina, N. A. (1997). Desulfonatronovibrio hydrogenovorans gen. nov., sp. nov., an alkaliphilic, sulfate-reducing bacterium. Int. J. Syst. Evol. Microbiol. 47, 144-149.

Conflict of Interest Statement: The authors declare that the research was conducted in the absence of any commercial or financial relationships that could be construed as a potential conflict of interest.

Copyright (C) 2016 Paul, Kumbhare, Mhatre, Chowdhury, Shetty, Marathe, Bhute and Shouche. This is an open-access article distributed under the terms of the Creative Commons Attribution License (CC BY). The use, distribution or reproduction in other forums is permitted, provided the original author(s) or licensor are credited and that the original publication in this journal is cited, in accordance with accepted academic practice. No use, distribution or reproduction is permitted which does not comply with these terms. 